\title{
An Occupant-Based Overview of Microplastics in Indoor Environments in the City of Surabaya, Indonesia
}

\author{
Intan Bahrina ${ }^{1}$, Arie Dipareza Syafei ${ }^{*}$, Rahmat Satoto ${ }^{2}$, Jheng-Jie Jiang ${ }^{3}$, \\ Nurul Rizki Nurasrin', Abdu Fadli Assomadi', Rachmat Boedisantoso', \\ Joni Hermana ${ }^{1}$, Muhamad Nasir ${ }^{2}$ \\ 1 Department of Environmental Engineering, Institut Teknologi Sepuluh Nopember, Sukolilo, Surabaya 60111, \\ Indonesia \\ 2 Research Unit for Clean Technology, Indonesian Institute of Sciences (LIPI) \\ ${ }^{3}$ Department of Environmental Engineering, Chung Yuan Christian University, Taoyuan 32023, Taiwan \\ * Corresponding author's e-mail: dipareza@enviro.its.ac.id
}

\begin{abstract}
Airborne microplastics smaller than $5 \mathrm{~mm}$ in diameter can be easily inhaled by humans, impacting their health. The human exposure to microplastics can occur in indoor environments, and this study investigated the degree of indoor deposition of microplastics in settled dust. The authors assessed the relationship between the number of occupants/people and the amount of microplastics in their indoor environment by determining the indoor microplastic exposure in two offices, two schools, and two apartments in Surabaya, Indonesia. The settled dust was collected using a vacuum cleaner for 10 minutes on a single weekday and the weekend at each study location. The results show that the amount of microplastics collected at each location during workdays exceeded the amount found on weekends. The two offices sampled were found to have the greatest amounts of microplastics ( 334 particles on a weekday, 242 particles on a weekend; and 351 particles on a weekday, 252 particles on a weekend), and the two apartments produced the least amounts of microplastics (133 particles on a weekday, 127 particles on a weekend; and 108 particles on a weekday, 95 particles on a weekend). The dominant microplastic shape was that of fiber, and the dominant size range of the microplastics collected was 3000-3500 $\mu \mathrm{m}$. The amount of indoor microplastics is influenced by the activities and the number of occupants/people in the space. The exposure levels indicated here will contribute to the formulation of the environmental health policy recommendations.
\end{abstract}

Keywords: dust, exposure, indoor, microplastic, Surabaya City

\section{INTRODUCTION}

Microplastics, with particles smaller than $5 \mathrm{~mm}$ [Dris et al. 2017], can pose a threat to the activities and health of humans [Eerkes-Medrano, Thompson, and Aldridge 2015]. The microplastic particles in the air can enter the respiratory system, where some inhalable particles will be deposited in the upper airway, while others will be deposited in the lungs, causing biological responses such as inflammation [Gasperi et al. 2018]. The results of one microscopic study of human lungs showed that $87 \%$ of the studied samples contained fibers [Pauly et al. 1998], with 97\% of malignant lung specimens containing fibers with lengths ranging from approximately $50 \mu \mathrm{m}$ to more than $250 \mu \mathrm{m}$ [Dris et al. 2017].

The microplastic exposure in the air depends on the distribution from the source. The microplastic sources in the air include plastic fragments from indoor furniture [Dris et al. 2016; Liebezeit and Liebezeit, 2015], landfills, material in buildings, incineration waste, particle resuspension, industrial emissions, and particles released by traffic [Dris et al. 2016]. Some studies detected the microplastic contamination possibly derived from clothes [Davison and Asch 2011; Foekema et al. 2013; Fries et al. 2013; Nuelle et al. 2014; Woodall et al. 2015]. 
Increased microplastic sources are associated with higher population densities. Any increase in the number of residents in a city results in increasingly diverse activities (both outdoors and indoors), which can cause a decline in the air quality [Browne et al. 2011]. Surabaya is the second-largest city in Indonesia and has a population of approximately 2 million people [BPS, 2020]. The photooxidation degradation of microplastics can occur, along with wind and abrasion of other particles in the ambient air, eventually resulting in fine airborne particles [Gasperi et al. 2018]. Most city dust is derived from polymerbased materials, i.e., microplastics [Verschoor et al. 2016], so it is potentially significant for the air quality of urban environments. Microplastics are abundant in indoor particulates because carpets, textiles (mats, furniture, clothing, curtains, mattresses), toys, rubber, kitchen tools (plates, cups, utensils, bowls, bottles, cutting boards, and so forth), electrical cables, electronics, indoor paint, cleaning agents, and other items contain plastic [Macher 2001; Bureau 2007; Webster et al. 2009]. One study reported that the fiber concentrations in the indoor settled dust collected from vacuum cleaner bags were higher ( 1 to 60 fibers $\left./ \mathrm{m}^{3}\right)$ than outdoors $\left(0.3\right.$ to 1.5 fibers $\left./ \mathrm{m}^{3}\right)$ [Dris et al. 2017]. The textile fibers in the dust that adhere to surfaces in homes in Norway were found to originate from indoor laundry rooms (the drying room/area is a significant source of textile fibers) [Sundt et al. 2014]. Hence, any city community can potentially be exposed to microplastics when indoors.

In recent years, there have been many studies on microplastics in the environment, but they have focused on aquatic environments [Cole et al. 2013]. The research on the microplastics in the indoor air is still insufficient, particularly considering that microplastics are abundant in the indoor dust. Therefore, this study was designed to contribute to the knowledge on the microplastics found in indoor air and determine the severity of the microplastic exposure in the indoor air as a basis for creating environmental health policies. Within this context, this study investigated the microplastics in indoor air in offices, schools, and apartments on weekdays and the weekend. Our goal was to investigate the relationship between the number of occupants/ people and the amount of microplastics in these indoor environments. Thus, three settings with different numbers of occupants/people were investigated, namely offices with 50-70 people, schools with 40 students/people, and apartments occupied by $1-2$ people.

\section{MATERIALS AND METHODS}

The study was conducted indoors in three different settings in the city of Surabaya, Indonesia (Table 1).

The samples were collected between July 16 and September 16, 2019. The samples were collected once for 10 minutes on workdays and the weekend at each study location. The level of indoor deposition of microplastics and their concentrations were investigated in the settled dust collected via a vacuum cleaner (Krisbow Turbo Tiger) and using new vacuum cleaner bags. The samples were taken directly from the vacuum cleaner bags, then subjected to density separation by mixing into $50 \mathrm{ml}$ of $\mathrm{ZnCl}_{2}\left(\mathrm{ZnCl}_{2}-1.6 \mathrm{~g} / \mathrm{cm}^{3}\right)$. The floating sample fraction was homogenized, and a subsample of $1 \mathrm{ml}$ was filtered through a GF/A Whatman fiberglass filter $(1.6 \mu \mathrm{m}$ pore size, $47 \mathrm{~mm}$ diameter).

All samples collected were observed visually under a digital microscope (Dino-Lite AM3113T) equipped with a software program (DinoCapture 2.0) to capture images from the observed samples. The microscopic images were used to determine the number of particles and physical shapes of the microplastics in a sample. The particles suspected of being microplastic were sorted and observed. The number of microplastic particles was calculated, and the microplastics were categorized based on their shapes and sizes.

\section{RESULTS AND DISCUSSION}

\section{Microplastic shapes}

The microscopic investigation included determination of the shapes of the microplastic particles collected at each study location. There were three (3) basic microplastic shapes discovered (Figure 2): fibers (Figure 2-a), fragments (Figure 2-b), and films (Figure 2-c). The pelletshaped microplastics were not found at any study location. Figure 2 shows the most abundant shape found in each sampling location was the fiber shape, accounting for $85 \%$ of the microplastic 
Table 1. Sampling Location and Sample Code

\begin{tabular}{|c|c|c|c|c|}
\hline Location & Longitude & Latitude & $\mathrm{D} / \mathrm{E}$ & $\begin{array}{c}\text { Location/ Sample } \\
\text { Code }\end{array}$ \\
\hline \multirow{2}{*}{ School 1 (S1) } & \multirow{2}{*}{$112^{\circ} 46^{\prime} 49.86^{\prime \prime} \mathrm{E}$} & \multirow{2}{*}{$7^{\circ} 17^{\prime} 18.87^{\prime \prime} \mathrm{S}$} & Day & S1D \\
\hline & & & End & S1E \\
\hline \multirow{2}{*}{ School 2 (S2) } & \multirow{2}{*}{$112^{\circ} 46^{\prime} 32.24^{\prime \prime} \mathrm{E}$} & \multirow{2}{*}{$7^{\circ} 17^{\prime} 14.61$ ' S } & Day & S2D \\
\hline & & & End & S2E \\
\hline \multirow{2}{*}{ Apartment 1 (A1) } & \multirow{2}{*}{$112^{\circ} 46^{\prime} 8.40^{\prime \prime} \mathrm{E}$} & \multirow{2}{*}{$7^{\circ} 17^{\prime} 22.88^{\prime \prime} \mathrm{S}$} & Day & A1D \\
\hline & & & End & A1E \\
\hline \multirow{2}{*}{ Apartment 2 (A2) } & \multirow{2}{*}{$112^{\circ} 47^{\prime} 12.45^{\prime \prime} \mathrm{E}$} & \multirow{2}{*}{$7^{\circ} 17^{\prime} 16.95^{\prime \prime} \mathrm{S}$} & Day & A2D \\
\hline & & & End & A2E \\
\hline \multirow{2}{*}{ Office 1 (O1) } & \multirow{2}{*}{$112^{\circ} 45^{\prime} 46.05^{\prime \prime} \mathrm{E}$} & \multirow{2}{*}{$7^{\circ} 16^{\prime} 42.16^{\prime \prime} \mathrm{S}$} & Day & O1D \\
\hline & & & End & O1E \\
\hline \multirow{2}{*}{ Office 2 (O2) } & \multirow{2}{*}{$112^{\circ} 50^{\prime} 41^{\prime \prime} \mathrm{E}$} & \multirow{2}{*}{$7^{\circ} 15^{\prime} 27.69^{\prime \prime} \mathrm{S}$} & Day & O2D \\
\hline & & & End & $\mathrm{O} 2 \mathrm{E}$ \\
\hline Note: $\mathrm{D}=$ weekday $; \mathrm{E}$ & & & & \\
\hline
\end{tabular}

particles (Table 2). This finding was consistent with the results of Dris et al. (2016) in Paris.

The dominant fiber shape can originate from synthetic clothing fabrics, fishing nets, household items, plastic bags, or weathered plastic products [Browne et al. 2011]. The fragment shape is derived from broken pieces of plastic from items such as bottles, jars, mica folders, pipe pieces, and other household appliances. The microplastic of the film shape is the result of the fragmentation of plastic bags or plastic packaging and has the lowest density.

\section{Quantity of microplastics}

The microscopic observations revealed that the offices (highest number of occupants/people) had the greatest amounts of microplastics (334 particles on a weekday and 242 particles on a weekend from site I; 351 particles on a weekday and 252 particles on a weekend from site II) and that the apartment (lowest number of occupants) had the fewest microplastics (133 particles on a weekday and 127 particles on a weekend from site I; 108 particles on a weekday and 95 particles

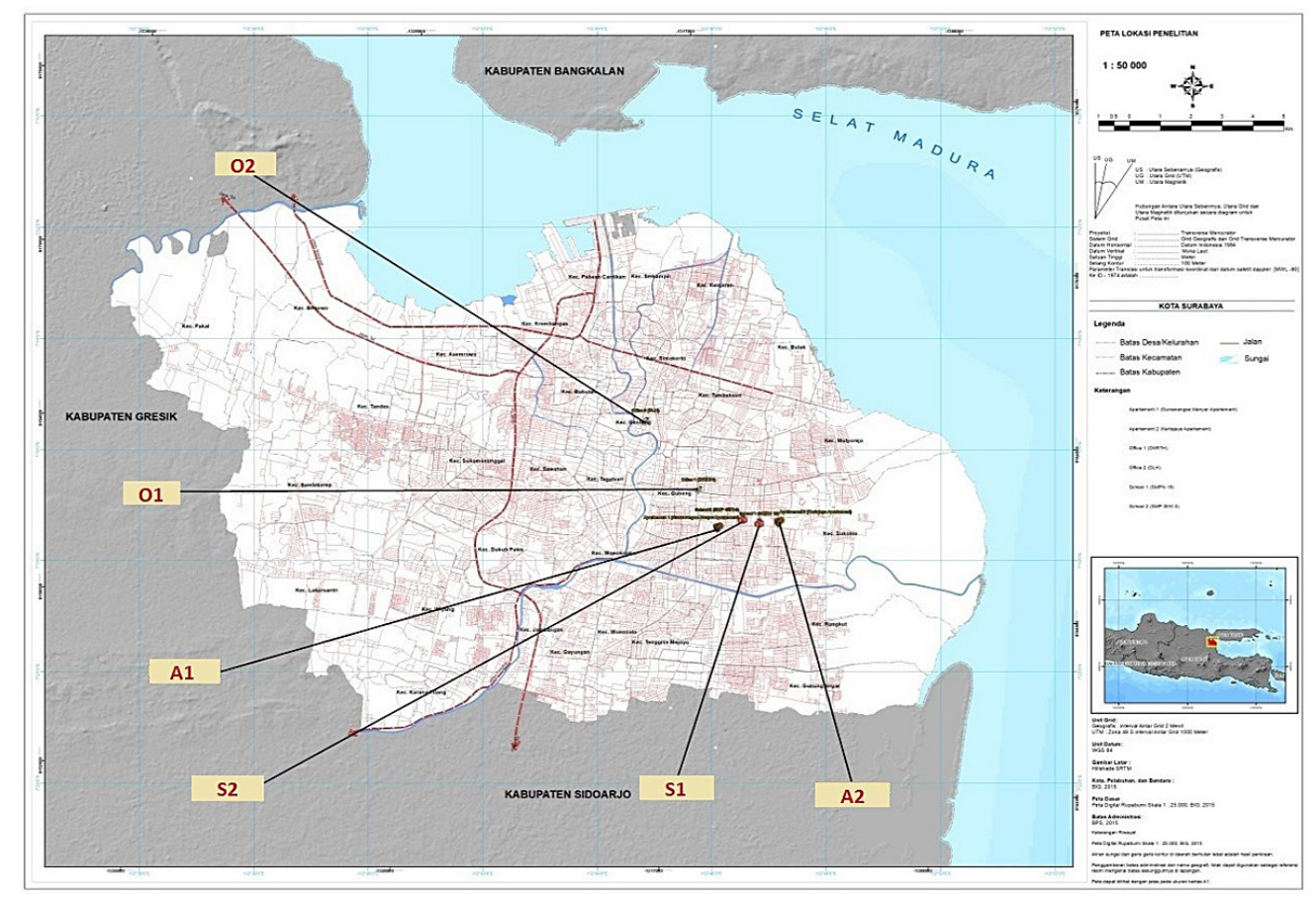

Figure 1. Indoor microplastic polymer sampling locations in Surabaya (S1; S2; A1; A2; O1; O2) 


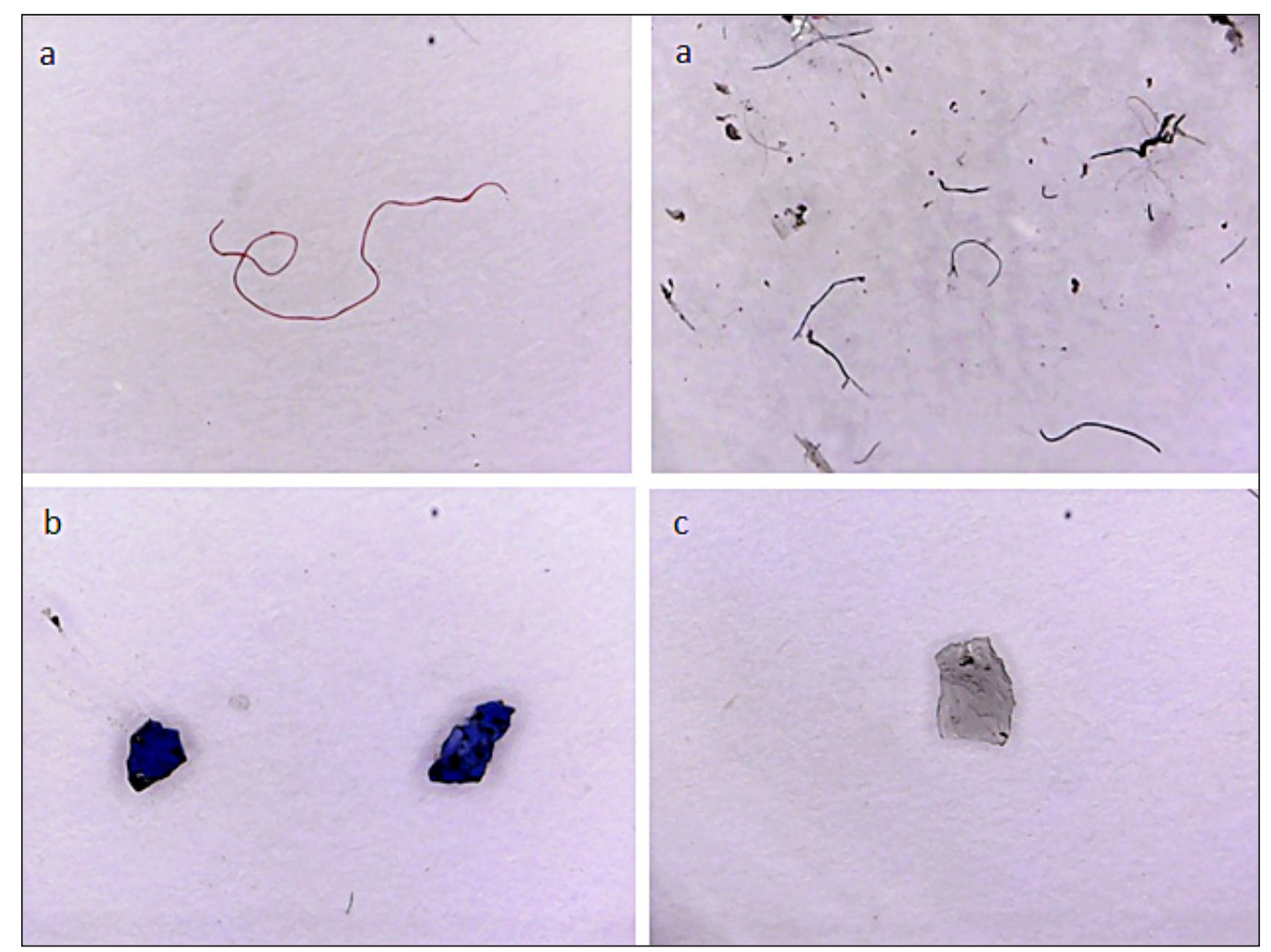

Figure 2. Shapes of the indoor microplastics in the city of Surabaya; a) fibers b) fragments c) films

on a weekend from site II) (Figure 3). For all samples, the quantity of microplastics collected at each location on a workday was greater than that collected on the weekend (Figure 3), revealing that the quantity of the indoor microplastics can be influenced by the number of occupants/ people and the activities taking place in the room. This conclusion is supported by Dris et al. (2017) and Magnusson et al. (2016). However, other factors, such as building materials, furniture, and cleaning habits, can also affect the amount of microplastics found.
The dominant microplastic size collected from all three settings over the workday and weekend was in the range of 3000-3500 $\mu \mathrm{m}$ (Figure 4). These particles should be too large to inhale, but the exposure can occur through dust consumption, especially by young children. Children can ingest the particulates or dust inadvertently via the insertion of dirty hands and/or toys or other objects into their mouths [Ljung et al. 2006]. Microplastic particles can undergo photooxidative degradation in the environment. This degradation, together with wind shear and/

Table 2. Microplastic quantities collected from each indoor study site in the city of Surabaya

\begin{tabular}{|c|c|c|c|c|c|c|c|}
\hline \multirow{2}{*}{\multicolumn{2}{|c|}{ Sites }} & \multirow{3}{*}{$\begin{array}{c}\text { Period } \\
\text { Weekday }\end{array}$} & \multicolumn{4}{|c|}{ Shape } & \multirow{3}{*}{$\begin{array}{c}\text { Total (particles) } \\
334\end{array}$} \\
\hline & & & \multirow{2}{*}{$\frac{\text { Fibers }}{316}$} & \multirow{2}{*}{$\frac{\text { Fragments }}{15}$} & \multirow{2}{*}{$\frac{\text { Films }}{3}$} & \multirow{2}{*}{$\frac{\text { Pellet }}{0}$} & \\
\hline \multirow{4}{*}{ Office } & \multirow{2}{*}{ I } & & & & & & \\
\hline & & Weekend & 236 & 5 & 1 & 0 & 242 \\
\hline & \multirow{2}{*}{ II } & Weekday & 334 & 12 & 5 & 0 & 351 \\
\hline & & Weekend & 238 & 5 & 9 & 0 & 252 \\
\hline \multirow{4}{*}{ School } & \multirow{2}{*}{ I } & Weekday & 244 & 29 & 17 & 0 & 290 \\
\hline & & Weekend & 213 & 16 & 10 & 0 & 239 \\
\hline & \multirow{2}{*}{ II } & Weekday & 303 & 7 & 11 & 0 & 321 \\
\hline & & Weekend & 234 & 10 & 13 & 0 & 257 \\
\hline \multirow{4}{*}{ Apartment } & \multirow{2}{*}{ I } & Weekday & 115 & 16 & 2 & 0 & 133 \\
\hline & & Weekend & 120 & 6 & 1 & 0 & 127 \\
\hline & \multirow{2}{*}{ II } & Weekday & 108 & 0 & 0 & 0 & 108 \\
\hline & & Weekend & 95 & 0 & 0 & 0 & 95 \\
\hline
\end{tabular}






Figure 3. Concentrations of the indoor microplastics in the city of Surabaya

or abrasion of other particulates in ambient air, will eventually lead to the occurrence of fine particles in the air [Gasperi et al. 2018]. Small microplastics can be easily ingested and inhaled by organisms, including humans [Gall and Thompson, 2015]. The smaller the microplastic particles, the more likely the particles are to be digested by an organism [Carson et al. 2013; Andrady, 2011]. The microplastic particles carried into the air will be inhaled and enter the airway [McCormick et al. 2014]. The microscopic observations of human lungs showed that $87 \%$ of the lungs studied $(n=114)$ contained fibers [Pauly et al. 1998].

\section{Strategies for reducing exposures to microplastics}

The potential sources of microplastics in the indoor dust are abundant because plastic can be found in carpets, toys, foam rubber, kitchen utensils (plates, cups, utensils, bowls, bottles, cutting boards, and so forth), electrical cables, electronics, textiles (mats, furniture, clothing, curtains, linen, mattresses), indoor paint, cleaning agents, and other items [Macher 2001; Bureau 2007; Webster et al. 2009]. In other words, the sources are virtually everywhere. The things that can be done to eliminate some of these sources include buying biodegradable clothes, i.e., the clothes made from natural fibers [Henry et al. 2018], and reducing the use of plastic bags, as people in Germany have done since 1991 [Lam et al. 2018].

However, other factors, such as building materials, furniture, and cleaning habits, can also affect the amount of microplastics found indoors. For this reason, it is necessary to maintain indoor cleanliness to reduce the exposure to microplastics. In addition, the furniture that is explicitly used for eating should be washed before use to avoid the exposure to ingestible microplastics transported by dust.

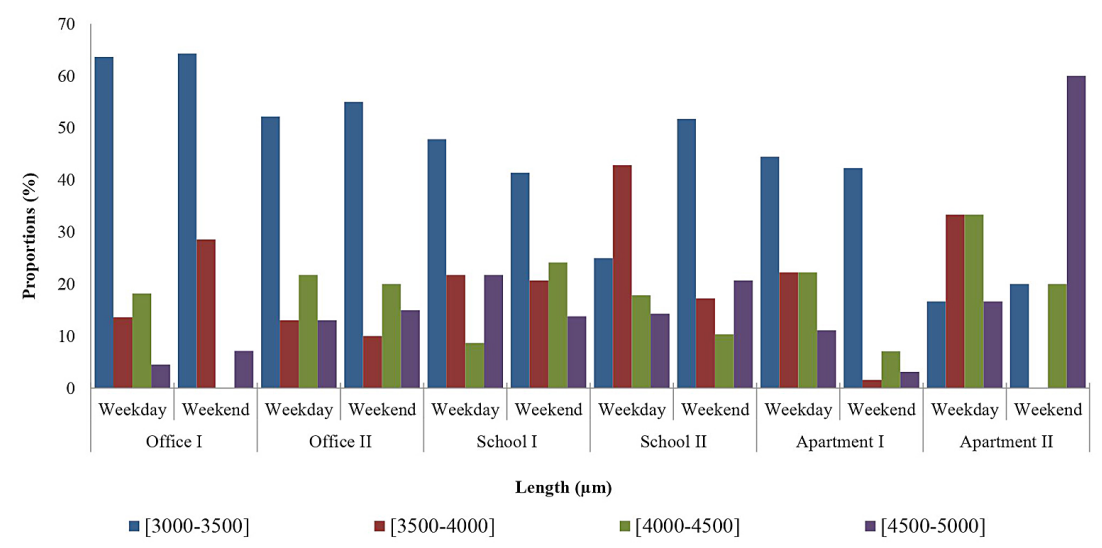

Figure 4. Size distribution of microplastics for each sampling site in the city of Surabaya 


\section{CONCLUSIONS}

There are abundant potential sources of microplastics in the indoor dust. This study showed that the microplastics present indoors in the city of Surabaya, Indonesia, were predominantly fiber-shaped, with microplastic particles identified as containing mostly plastic polymers. A greater number of occupants/people within an indoor space results in an increased quantity of microplastics. The products made of plastic, such as carpets, toys, furniture, kitchen tools, electrical cables, electronics, textiles, indoor paints, cleaning materials, and more, contribute to the amount of microplastics found indoors. The daily indoor activities and the use of plastic products will inevitably lead to the release of microplastics that settle in the indoor dust. Therefore, further research on specific microplastic sources is also needed to determine the prevalence of specific types of microplastic from each source.

\section{Acknowledgments}

We wish to convey sincere gratitude to the Department of Environmental Engineering, Faculty of Civil, Environmental, and Geo Engineering, Institut Teknologi Sepuluh Nopember (ITS), for research support, especially facilities provided. We also thank the Directorate of Research and Community Services, Directorate General of Research and Development, Ministry of Research, Technology, and Higher Education of the Republic of Indonesia under which they provided us funding for a research project titled Microplastic in Indoor, contract 774/PKS/ITS/2019 and 5/E1/KP.PTNBH/2019.

\section{REFERENCES}

1. Andrady, A.L. 2011. Microplastics in the marine environment. Marine Pollution Bulletin, 62(8), 1596-1605.

2. BPS-Statistics Of Surabaya Municipality. 2020. Surabaya Municipality In Figures.

3. Browne, M.A., Crump, P., Niven, S. J., Teuten, E., Tonkin, A., Galloway, T., \& Thompson, R. 2011. Accumulation of microplastic on shorelines woldwide: Sources and sinks. Environmental Science and Technology, 45(21), 9175-9179.

4. Bureau, I. 2007. WO 2007/079027 A2 (81). 2007 (July).
5. Carson, H.S., Nerheim, M.S., Carroll, K.A., \& Eriksen, M. 2013. The plastic-associated microorganisms of the North Pacific Gyre. Marine Pollution Bulletin, 75(1-2), 126-132.

6. Cole, M., Lindeque, P., Fileman, E., Halsband, C., Goodhead, R., Moger, J., Galloway, T.S. 2013. Microplastic ingestion by zooplankton. Environ. Sci. Technol, 47, 6646-6655.

7. Davison, P., \& Asch, R.G. 2011. Plastic ingestion by mesopelagic fishes in the North Pacific Subtropical Gyre. Marine Ecology Progress Series, 432, 173-180.

8. Dris, R., Gasperi, J., Mirande, C., Mandin, C., Guerrouache, M., Langlois, V., \& Tassin, B. 2017. A first overview of textile fibers, including microplastics, in indoor and outdoor environments. Environmental Pollution, 221, 453-458.

9. Dris, R., Gasperi, J., Saad, M., Mirande, C., \& Tassin, B. 2016. Synthetic fibers in atmospheric fallout: A source of microplastics in the environment?. Marine Pollution Bulletin, 104(1-2), 290-293.

10. Eerkes-Medrano, D., Thompson, R.C., \& Aldridge, D.C. 2015. Microplastics in freshwater systems: A review of the emerging threats, identification of knowledge gaps and prioritisation of research needs. Water Research, 75, 63-82.

11. Foekema, E.M., Gruijter, C.D., Mergia, M.T., Franeker, J.A. Van, Murk, A.J., \& Koelmans, A.A. 2013. Plastic in North Sea Fish. Environmenrtal Science \& Technology, 47, 8818-8824.

12. Fries, E., Dekiff, J.H., Willmeyer, J., Nuelle, M.T., Ebert, M., \& Remy, D. 2013. Identification of polymer types and additives in marine microplastic particles using pyrolysis-GC/MS and scanning electron microscopy. Environmental Sciences: Processes and Impacts, 15(10), 1949-1956.

13. Gall, S.C., \& Thompson, R.C. 2015. The impact of debris on marine life. Marine Pollution Bulletin, 92 (1-2), 170-179.

14. Gasperi, J., Wright, S.L., Dris, R., Collard, F., Mandin, C., Guerrouache, M., Langlois, V., Kelly, F.J., \& Tassin, B. 2018. Microplastics in air: Are we breathing it in?. Current Opinion in Environmental Science and Health, 1, 1-5.

15. Henry, B., Laitala, K.., \& Klepp, I.G. 2018. Microplastic pollution from textiles: A literature review (Issue 1). www.sifo.no

16. Lam, C.S., Ramanathan, S., Carbery, M., Gray, K., Vanka, K.S., Maurin, C., Bush, R., \& Palanisami, T. 2018. A Comprehensive Analysis of Plastics and Microplastic Legislation Worldwide. Water, Air, and Soil Pollution, 229(11).

17. Liebezeit, G., \& Liebezeit, E. 2015. Origin of synthetic particles in honeys. Polish Journal of Food and Nutrition Sciences, 65(2), 143-147 
18. Ljung, K., Selinus, O., Otabbong, E., \& Berglund, M. 2006. Metal and arsenic distribution in soil particle sizes relevant to soil ingestion by children. Applied Geochemistry, 21 (9), 1613-1624.

19. Macher, J.M. 2001. Review of methods to collect settled dust and isolate culturable microorganisms. Indoor Air, 11(2), 99-110.

20. McCormick, A., Hoellein, T.J., Mason, S.A., Schluep, J., \& Kelly, J. J. 2014. Microplastic is an abundant and distinct microbial habitat in an urban river. Environmental Science and Technology, 48(20), 11863-11871.

21. Nuelle, M.T., Dekiff, J.H., Remy, D., \& Fries, E. 2014. A new analytical approach for monitoring microplastics in marine sediments. Environmental Pollution, 184, 161-169.

22. Pauly, J.L., Stegmeier, J., Cheney, T., Zhang, P. J., Allaart, A., \& Mayer, G. 1998. Inhaled Cellulosic and Plastic Fibers Found in Human Lung Tissue. Cancer Epidemiology, Biomarkers Prev, 7, 419-428.
23. Sundt, P., Schultze, P.E, Frode. S. 2014. Sources of microplastic- pollution to the marine environment. Mepex, Norwegian Environment Agency, 1-108.

24. Verschoor, A., De Poorter, L., Dröge, R., Kuenen, J., \& De Valk, E. 2016. Emission of microplastics and potential mitigation measures (cleaning agents, paints and tyre wear). 76 .

25. Webster, T.F., Harrad, S., Millette, J.R., Holbrook, R.D., Davis, J.M., Stapleton, H.M., Allen, J. G., McClean, M.D., Ibarra, C., Abdallah, M.A.E., \& Covaci, A. 2009. Identifying transfer mechanisms and sources of decabromodiphenyl ether (BDE 209) in indoor environments using environmental forensic microscopy. Environmental Science and Technology, 43(9), 3067-3072.

26. Woodall, L.C., Gwinnett, C., Packer, M., Thompson, R.C., Robinson, L.F., \& Paterson, G.L.J. 2015. Using a forensic science approach to minimize environmental contamination and to identify microfibres in marine sediments. Marine Pollution Bulletin, 95(1), 40-46. 